\title{
Generic drugs in Canada: an examination of tiered pricing
}

\author{
Aidan Hollis PhD
}

$\mathrm{T}$ he Council of the Federation (i.e., the premiers of all provinces and territories in Canada) recently finalized a deal with generic drug manufacturers to reform the reimbursement scheme for generic drugs. ${ }^{1}$ The new scheme involving tiered pricing has a threeyear duration and was adopted by all of the provinces except Quebec. This offers stability and allows for assessment of the pricing scheme in practice. The design is simple: if one manufacturer of generic drugs enters the market for a drug, the price falls to $75 \%$ of the price of the brand-name drug; if two manufacturers enter the market, the price falls to $50 \%$; and if three or more enter the market, the price falls to $25 \%$. A reimbursement rate of $18 \%$ of the price of the brand-name drug was set for a number of high-volume products. The new arrangement is an improvement over earlier strategies for price setting, but it does not go far enough.

From 2007 to 2013, provincial drug plans pursued ad hoc price reductions in the generic drug market, which led to considerable uncertainty and different pricing levels across provinces. Most provinces used a fixed-price system, in which the price of the generic drug was a fixed ratio of the price of the brand-name drug (e.g., $25 \%$ or $35 \%$ ) regardless of how many manufacturers offered the drug. Fixed pricing created problems when the costs of producing a generic drug were high and led manufacturers to apply for exemptions from the fixed-price limit. This led to a situation in which the government had to assess the cost of manufacture and, in effect, engage in utility-style, cost-based regulation of many generic drugs.

The new scheme closely follows a pricing model first proposed for Canada in $2009,{ }^{2,3}$ and it represents a substantial improvement over the fixed-price system. The basic idea is that manufacturers will continue to enter the market as long as their costs are below the mandated price. Manufacturers will find it profitable to enter the market if their costs are still below the next price tier. In effect, the new system simulates competitive pricing because prices will be close to the competitive level. Moreover, the system will operate automatically and without the provincial insurers needing to know the cost of manufacturing: the cost range can be inferred by the number of firms entering a particular drug market. (Austria uses a similar system for its small generic drug sector, with a less aggressive pricing structure. ${ }^{4}$ )

However, the new pricing policy implemented by the provinces is designed to stop after three generic entrants. This leaves the potential for ongoing big profit margins, because the production cost for many generic products is far below $25 \%$ of the price of the brand-name drug. For many generic drugs, production costs may be closer to $2 \%$ or $3 \%$ of the price of the brand-name drug, which is generally related to the insurers' willingness to pay and not to the cost of production. ${ }^{5}$

Generic drugs that are priced above cost cause the manufacturers of generic drugs to compete aggressively for a share of the market by granting confidential discounts to pharmacies to stock their products. ${ }^{6}$ Although some provinces (e.g., Ontario) have attempted to prevent this type of discounting through regulation, it is difficult to stop profitable transactions between willing parties. ${ }^{7}$ This results in a large share of reimbursed prices being captured by pharmacies and not as price reductions accruing to the benefit of the drug plans, insurers or patients. This failure to achieve low prices means that provinces have an incentive to try something else to save money. For example, the British Columbia drug plan defected from the new scheme ${ }^{8}$ and recently tendered seven products (celecoxib, topiramate, zolmitriptan ODT, alendronate, fluoxetine, escitalopram and quetiapine) for sole supply. Therefore, the BC public insurance program will only cover purchases of the winning bidder's product. This approach should achieve much lower prices for those drugs, given that the new tiered-pricing approach has a high lower

\section{Ker POINTS}

- The Canadian provinces, with the exception of Quebec, have agreed to a three-year, tiered-pricing arrangement for generic drugs, in which prices are dependent on the number of manufacturers in the marketplace for a particular drug.

- The tiers are set at $75 \%, 50 \%$ and $25 \%$ of the price of the brand-name drug when one, two, and three or more manufacturers enter the market for a drug, respectively.

- The lowest tier is high: additional tiers are needed to capture the benefits of competition.
Competing interests:

Aidan Hollis has received consultant fees from Industry Canada and the Canadian Generic Pharmaceutical Association, and speaker fees from the Organisation for Economic

Co-operation and Development, and the Chain Drug Stores. He has received renumeration as an expert witness on behalf of Apotex, Cobalt Pharmaceuticals, Sandoz and Teva Canada.

This article has been peer reviewed.

Correspondence to:

Aidan Hollis,

ahollis@ucalgary.ca

CMAJ 2015. DOI:10.1503 /cmaj.150395 Canadian Association of 
limit on prices. However, this does not mean that the tendering system is an improvement.

The main concern with tendering is its effect on incentives to challenge patents on existing brandname drugs. ${ }^{9}$ Canadian laws and regulations protecting brand-name drugs are complex, but it is sufficient to understand that most important drugs are protected by a web of patents with varying expiry dates and effectiveness in preventing generic entry. Thus, for many drugs - and certainly for most high-volume drugs - patent litigation is a precondition for generic competition. Not all of the patents simply expire before generic entry: the first generic entrants often face a patent hearing in court and, if they are allowed to enter the market, a patent infringement lawsuit. This is costly because it requires the generic drug manufacturer to commit substantial time and out-of-pocket expenses for intellectual property lawyers and expert witnesses. The litigation costs can run into the millions of dollars. If the generic drug manufacturer loses, it may suffer large financial losses. If it wins, it gets to produce a generic drug and enter the market. The benefits of entry mostly accrue to payers through reduced prices, but the generic drug manufacturer that challenged the patent can still make some profit under the system of tiered pricing, because the first entrant will typically retain a large share of the market even if other generic drug manufacturers enter and drive down prices. ${ }^{10}$ The tender process puts these incentives at risk: generally, the firm that challenged the patent has no advantage over other firms and will have had higher costs because of litigation. No rational generic drug manufacturer would invest in a risky patent challenge for a prize worth nothing. For the present, BC has avoided creating these problems, because six of the seven products that it has tendered did not become generics owing to generic litigation, but this is not a common situation with major drugs. (The exception is alendronate, which became a generic in 2005.)
Is there a path to progress? The tiered-pricing design needs to be adjusted to allow for additional tiers as more manufacturers enter the market. If each additional entrant after the first three reduced the price by $5 \%$, it would drive prices down on the largest products with multiple suppliers and low costs of production. The first entrants, who deliver benefits to payers by challenging patents and early entry, would be rewarded. At the same time, payers and patients would obtain competitive prices that reflect the costs of supply.

\section{References}

1. Keon J. Getting to the heart of sustainability - the issues. Canada's public policy forum - Atlantic summit on healthcare and drug cost sustainability; 2014 Oct. 30; Charlottetown (PEI). Toronto: Canadian Generic Pharmaceutical Association; 2014 Available: www.canadiangenerics.ca/en/news/docs/10.30.14\% 20AtlanticCanadaSummit.pdf (accessed 2015 June 3).

2. Hollis A. Generic drug pricing and procurement: a policy for Alberta. School of Public Policy Studies: SPS Research Papers 2009;2:1-53. Available: www.policyschool.ucalgary.ca/sites /default/files/research/hollis-online-feb-09.pdf (accessed 2015 May 22).

3. Grootendorst P, Hollis A. Managing pharmaceutical expenditure: an overview and options for Canada. Ottawa: Canadian Health Services Research Foundation; 2011.

4. Leopold C, Habl C, Morak S. Pharmaceutical pricing and reimbursement information. Vienna: Gesundheit Österreich $\mathrm{GmbH}$ / Geshäftsbereich ÖBIG; 2008. Available: http://whocc.goeg.at /Dokumente/CountryInformationReports/Austria_PPRI_2008_ German_Version.pdf (accessed 2015 June 2).

5. Law MR. Money left on the table: generic drug prices in Canada. Health Policy 2013;8:17-25.

6. Canadian Generic Drug Sector Study. Ottawa: Competition Bureau Canada; 2007.

7. Silversides A. Ontario's law curbing the cost of generic drugs sparks changes for pharmacies and other Canadian buyers. CMAJ 2009;181:2008-10.

8. PharmaCare deal for seven drugs saves millions, ensures supply [press release]. Vancouver: BC Ministry of Health; 2015. Available: www2.news.gov.bc.ca/news_releases_2013-2017 /2015HLTH0009-000234.htm (accessed 2015 Apr. 3).

9. Hollis A, Grootendorst P. Tendering generic drugs: What are the risks? Toronto: Canadian Generic Pharmaceutical Association; 2012. Available: www.canadiangenerics.ca/en/advocacy/docs /10.24.12 Tendering Generic Drugs - What Are the Risks_ FINAL.pdf (accessed 2015 June 2).

10. Hollis A. The importance of being first: evidence from Canadian generic pharmaceuticals. Health Econ 2002;11:723-34.

Affiliation: Department of Economics, University of Calgary, Calgary, Alta. 